\title{
Learning outcomes, learning support and cohort cohesion on a virtual field trip: an analysis of student and staff perceptions
}

\author{
Clare E. Bond ${ }^{1}$, Jessica H. Pugsley ${ }^{1}$, Lauren Kedar ${ }^{1}$, Sarah R. Ledingham ${ }^{1}$, Marianna Z. Skupinska ${ }^{1}$,
} 5 Tomasz K. Gluzinski ${ }^{1}$, Megan L. Boath ${ }^{1}$.

${ }^{1}$ School of Geoscience, University of Aberdeen, Kings College, Aberdeen, AB24 3UE, UK

Correspondence to: Clare E. Bond (clare.bond@abdn.ac.uk)

10 Abstract. The rise of the virtual field trip was unprecedent in 2020 and 2021 due to the global COVID-19 pandemic. Virtual field trips aim to replicate the learning outcomes and experiences of actual field trips, by providing a digital alternative to infield courses. They provide valuable opportunities for those unable to visit the field and alternative learning experiences for those that can. However, understanding their efficacy in term of learning outcomes, the effectiveness of learning support offered, and cohort cohesion generally remains untested. Here we show how negative aspects of a virtual field trip both pre-

15 and post-course are countered by positive outcomes in terms of breadth of learning outcomes and experience. As part of our analysis, we tested methods to mitigate barriers to inclusion and learning on a virtual field trip including internet connectivity and hardware access, use of printed workbooks, and limitations to interaction, support and cohort cohesion. Our results show that although negative perceptions, as evidenced through questionnaire responses, are dominant, with $71 \%-88 \%$ of respondents commenting on these aspects across both student and staff cohorts pre- and post-course; positive aspects of virtual field trips

$20(43 \%-57 \%)$ also feature highly. Students show a positive shift in their perception of online teaching and learning over the course with positive comments moving from $19 \%$ pre-course to $71 \%$ post-course, whereas positive comments by staff are low pre- and post-course at $14 \%$. Printed workbooks, staff: student ratios and interaction are received positively. Overall, we find that negative perceptions of virtual field trips pre- and post-course exist, but that both students and staff identify positive elements including breadth of learning outcomes, particularly regarding data synthesis and analysis. We suggest ways to learn from these findings to design virtual field trips that deliver effectively in blended learning environments for the benefit of all.

\section{Introduction}

Geological fieldwork in the years 2020 and 2021 has been significantly impacted by the COVID-19 global pandemic (Arthurs, 2021, Rotzein et al., 2021). In the United Kingdom this resulted in the country going into 'lockdown', an effective stay at 30 home order, restricting travel and social interaction, from late March 2020 (Iacaobucci, 2020). Other countries were similarly 
https://doi.org/10.5194/gc-2021-36

Preprint. Discussion started: 8 October 2021

(c) Author(s) 2021. CC BY 4.0 License.

(c) (i)

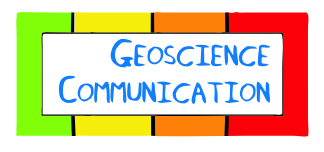

Discussions

affected. The result was no geological fieldwork could be undertaken, with many undergraduate programmes heavily reliant on summer fieldwork placed in jeopardy. For undergraduate students at the end of their penultimate BSc year this placed them, and staff, in the difficult position of missed credits from Easter and early summer field trips. With no likelihood of a summer mapping camp, or dissertation, students were on track to enter their final year with significant credit deficit and minimal field experience.

Virtual outcrops and virtual learning environments had slowly been developing over recent decades (Hurst, 1998, Tuthill and Klemm, 2002, Pringle et al., 2004, Trinks et al., 2005, Buckley et al. 2010 Çaliskan, 2011, Tibaldi et al. 2021), with increasing use and application in research (Casini et al. 2006; Cawood et al., 2017), teaching (Tibaldi et al. 2020, Bond and Cawood,

40 2021) and conservation (Martínez-Graña et al., 2013, Pasquaré Mariotto et al., 2021). The effectiveness of virtual outcrops and virtual field trips had been, comparatively to actual in-field experiences, little evaluated. But with almost $100 \%$ change in the sector from actual to virtual field trips overnight in early 2020 there are now a growing number of publications and papers in this area (Mead et al. 2019, Whitmeyer and Dordevic, 2021, Bond and Cawood, 2021, Bos et al., 2021), of which papers in this volume are an example. At the University of Aberdeen, in common with many academic institutions, staff moved quickly

45 to replace field training with virtual alternatives. In many respects Aberdeen was well placed with existing expertise and resources in virtual outcrop model creation and use, and with open access models that could be used by the broader geological community (e.g. eRock; www.e-rock.co.uk, see also Cawood and Bond (2019) and v3Geo www.v3geo.com see Buckley et al., this volume), as were the students who had previous expertise in using online resources such as the UK virtual microscope www.virtualmicroscope.org and the virtual seismic atlas www.seisimcatlas.org.

Rather than focus on the design and delivery of the geological elements of the virtual field trip, in this contribution we consider the issues of: 1) internet connectivity, 2) student perceptions and 3) staff perceptions on learning outcomes, learning support and cohort cohesion, with a view to learning to inform future virtual field trip delivery. Internet connectivity and digital infrastructure, have been identified as a barrier to education with, implications for equality, diversity and inclusion (Laksana,

55 2021, Pearson and Reddy, 2021, Devkota, 2021, Ochieng and Gyasi, 2021), and although many examples focus on developing countries, similar issues are found in the most advanced global economic countries (e.g. Sanders and Scanlon, 2021). Internet connectivity is essential for the delivery of online courses and for the real time use of 3D virtual outcrop models during virtual field trips. In this regard digital resource is particularly pertinent to the delivery of virtual field classes as they can require significant internet speeds for live streaming. The rendering of 3D geological models also often requires 'higher-end' graphics 60 cards, causing specific challenges. Such digital capacities in education are an issue identified and outlined in detail by Abduvakhidov et al. (2021). Here we are interested in the impact on student learning and student satisfaction/dissatisfaction of the course arising from digital infrastructure. 
https://doi.org/10.5194/gc-2021-36

Preprint. Discussion started: 8 October 2021

(c) Author(s) 2021. CC BY 4.0 License.

(c) (i)

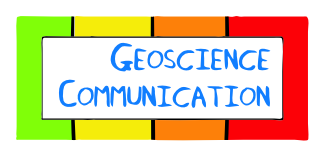

Discussions

Our second focus, 2) Student perceptions of the programme, and the challenges they would face in completing a fully online

65 virtual field course; was chosen as perceptions have important implications for learning ability. Evidence from pedagogic studies show, that student concerns around learning environments, cultures and other stresses have an impact on learning ability (Hess, 2002, Christie et al., 2008, Xia, 2009). Effectively being placed in an unfamiliar environment increases the mental load and reduces capacity for engagement in learning. Pre-fieldwork anxiety has been demonstrated for students who are, for example, unfamiliar with fieldwork and/or the outdoors, or are concerned about the use of shared facilities on a field trip. (Boyle et al., 2007, Stokes and Boyle, 2009). Although familiar in one sense, working from home during COVID-19 was unfamiliar and uncertain, as was the delivery of a new and alternative course in a novel format using new software at short notice. The online environment also brings different challenges to learning including lack of connections and cohort cohesion (Tinto, 2008, Cleveland-Innes and Campbell, 2012). We were interested in how the perceptions of students influenced their learning in this unfamiliar environment. Similarly, we considered, 3) staff perceptions of the programme and delivery challenges. We were interested to see if student perceptions pre-course mirrored those of staff and if likely challenges identified by staff and associated mitigation strategies were apparent and effective respectively. We also aimed to capture if and how perceptions of staff and students changed over the programme.

To evaluate the three foci outlined we designed three online surveys. Here we reflect on the outcomes of those three surveys, discussing the implications for learning and teaching in new formats, drawing out the potential benefits and challenges of different approaches and how staff and student perceptions changed.

\section{Course Design}

After 'lockdown' was announced a group of staff worked as a team, over the subsequent six-week period, to develop a fiveweek training program that would directly replace a two-week field trip. The original field trip was designed for penultimate 85 year undergraduate students, in the NW Highlands of Scotland, and had previously acted as precursor to their final year sixweek individual mapping dissertation. Significant consideration was given to the length and format of the replacement online training, with a longer programme eventually favoured for inclusion purposes (e.g., students ill with COVID, students working in critical supply chain jobs, and students with caring responsibilities (schools and other facilities were closed)). This allowed a format of two recorded 'kick-off' sessions a week, essentially 10 work elements over the five-week period, with drop-in

90 sessions at various times, including some evening sessions, to accommodate the diversity of individual situations, and availability, within the student cohort.

An initial exercise was undertaken amongst the staff team to consider the learning outcomes of the 'actual' field trip and how these mapped onto the possibilities for delivery in a virtual environment. Through the series of activities designed the staff team felt that all the learning outcomes could be achieved, apart from actually physically 'to observe rocks in their context in 
https://doi.org/10.5194/gc-2021-36

Preprint. Discussion started: 8 October 2021

(c) Author(s) 2021. CC BY 4.0 License.

(c) (i)

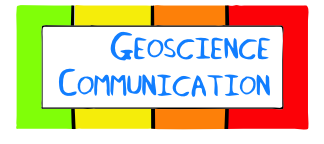

Discussions

the field'; although this could be done virtually. Alongside the geological learning outcomes was consideration of how academic and peer support could be used in a virtual environment to best achieve the learning outcomes and build cohort cohesion. These latter elements were in many ways more challenging; the logistics of effective learning strategies with the external factors and uncertainty related to delivery during the early weeks of the COVID-19 pandemic, including a five-week long programme with potential for fragmented learning and little cohort cohesion were concerns. Mitigations to address these concerns were built into the programme design. Further concerns included the internet connectivity of students and staff to attend and deliver the programme.

The issue of the potential impact of internet connectivity was addressed immediately as this would inform course design and delivery. An initial questionnaire was conducted to test students' internet connection speeds: download-speed, upload-speed and latency (through a linked testing service), to determine what computer hardware they had access to, and to find out about their daily availability over the duration of the course. We were also conscious that the students would be facing potentially new and additional challenges during the course and included a free form question entitled 'Other Issues' in which we asked students to "highlight any other issues that you feel you may have in completing the work (e.g., childcare commitments, keyworking, lack of quiet spaceltime to work - note that these are just examples, this list is not exhaustive). Please give as much information as possible as to how any issues raised will likely affect you." This initial questionnaire was completed by all students on the course.

\section{Eliciting Perceptions}

\subsection{Questionnaire Design}

The main dataset analysed in this paper was sourced from two sets of online questionnaires sent to the students' and staff

115 participating in and delivering the course. Participation in the questionnaire's was voluntary. The first 'pre-course' questionnaire focused on participants' views on: the learning outcomes of the trip, learning support (i.e., peer-peer and academic-student interactions), as well as some of the logistics and challenges associated with online-distance learning, particularly virtual field trips. The questionnaires started with two questions that elicited student and staff perceptions using an open text box response on the positive and negative aspects of a virtual field course. The questions were: "What do you think the positive aspects of a virtual field course might be?" and "What do you think the negative aspects of a virtual field course might be?". Participants were then asked to answer to what extent they agreed with 25 statements (Supplementary Material) using a numerical response between 1 and 5, corresponding to how much they agreed with the statement. Additionally, the questionnaires also contained an open text box at the end in which participants could add qualitative statements to elaborate on their quantitative answers, allowing participants to highlight any areas they felt were important but that had not been raised by the questionnaire statements. The student and staff questionnaires mirrored each other and were simply phrased for participation and delivery respectively. The second 'post-course' questionnaire was circulated after the 
https://doi.org/10.5194/gc-2021-36

Preprint. Discussion started: 8 October 2021

(c) Author(s) 2021. CC BY 4.0 License.

(c) (i)

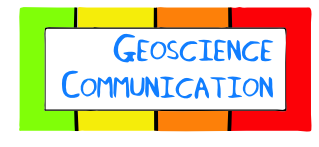

Discussions

course and focused on the same statements as presented in the 'pre-course' questionnaire, but from the new perspective of having completed the course or, for staff, having delivered it. It is important to state that not all student participants completed the pre-course questionnaire in advance of the course, and the answers of some participants might have been influenced by attendance in the initial week's session prior to questionnaire completion.

The questionnaire design and the statements for which perceptions were elicited were informed by the original field trip learning outcomes. Further developed by staff discussions during the design of the programme that reflected concerns with delivery of the learning outcomes and associated factors such as cohort cohesion and the logistics and issues of virtual field trip delivery. In summary, the statements fell into three broad categories: i) learning outcomes, ii) peer-peer and academic support, and iii) logistics. The full set of questionnaires can be found in the supplementary material. Questionnaires eliciting perceptions were answered anonymously.

\subsection{Questionnaire Analysis}

Numerical answers to the statements by participants were summed, with average and inter-quartile ranges calculated and plotted in box and whisker format to show the range in perceptions of staff and students pre- and post-course to the 25 elicited statements. In contrast, the free text comments required coding before analysis. The initial codes were developed by two of the author team, who defined a set of correlative codes that spanned the range of respondent opinions, both positive and negative. The coding was designed so that multiple codes could be assigned to each comment to capture the breadth of respondent perceptions during coding. Codes were then checked by the full author team to ensure they were relevant, and their descriptors were explanatory. Detailed reflection and refinement resulted in a final set of ten codes and associated descriptors, that effectively captured the critical elements of participants' comments. Codes were not explicitly designed to be paired. However, eight of the ten codes were effectively poistive and negative pairs. These were: accessibility, equality, inclusion; time management; aspects of online teaching and learning; aspects of the virtual field trip. The codes were then applied to the qualitative free text responses by the author team, as three pairs and one individual to generate a set of codes for each participants' free text. The four sets of codes were then compared, discrepancies were minor. The full-author team met and reviewed the codes and agreed on a final set of codes for each free text response.

\section{Internet access, student availability and other issues}

\subsection{Internet Access}

Students participating in the course were based in locations across the UK and Europe. Tests of the students' internet quality (download-speed, upload-speed and latency) established that the overall quality of internet in the student cohort was poor compared to published data from speedtest.net accessed 05/2021, with results obtained for global averages in May 2020 and similarly from Ofcom for the UK (www.ofcom.org.net; accessed 05/2021, with results obtained for 05/2020) Figure 1a). The 
https://doi.org/10.5194/gc-2021-36

Preprint. Discussion started: 8 October 2021

(c) Author(s) 2021. CC BY 4.0 License.

average UK upload-speed in May 2020 falls outwith the upper quartile of student speeds and for download-speeds the UK average at that time was bettered by the only student with an ether-net cable who had the fastest download speed in the cohort. It is worth noting that students had been asked to test internet connectivity at a time during the day when they were likely to be attending the programme. We also recognize that home-internet at the time was under significant stress, with the potential for several working adults on video-calls during the daytime on one home-internet connection. During the live sessions it was clear that some participants had issues with connectivity, identified by a red poor connection signal within the virtual classroom environment used for delivery. Evidence from the virtual classroom software suggests that these problems were however very limited with most students connecting just once to live sessions (Figure 1b). The data presented in Figure 1b) is for 22 live sessions over the duration of the five-week virtual field trip. We assume that those joining once or twice are joining and leaving sessions at will, whereas those joining 3 or more times are having connectivity or software issues. Note that of the 180 total joins to sessions 155 were single joins and 18 were double joins, with only 7 joins falling into the $3+$ category. This also implies that for students who did on occasion experience issues, that these were not persistent over the virtual field trip.

A series of mitigation measures were designed into the course to minimize the potential impact of internet connectivity issues, as well as the effectiveness of the hardware which the students had access to. Each live introductory session was recorded for student access after delivery. Similarly, question and answer sessions were also recorded. The only sessions not consistently recorded were smaller group sessions led by PhD students. A printed work booklet was sent to all students in advance of the course, this contained a timetable of activities, each sessions explanatory sheets, information on formative and summative assessments, and session material e.g., detailed photographs and maps. This helped mitigate potential internet and hardware issues, for example, to render 3D models and visualizing images; and given that most of the students were working on laptops, with a single relatively small screen, it allowed them to refer to material whilst also seeing the staff in a live video stream or looking at a virtual outcrop model. Some sessions required: Google Earth, the session instructions (PDF format), virtual outcrop models and detailed photographs, so having access to some of that material in hard copy was useful, ensuring that more than one element could be considered at the same time.

\subsection{Student availability and other issues}

There was a range in student availability with many students under-taking key-worker roles in critical service sectors whilst others effectively had nothing to do. Other issues identified by the students were: Wi-Fi variability, childcare and a quiet

185 working space. These issues were compounded by many students having returned to their family homes with multiple adults working at home online, and/or the presence of younger siblings. Most of the mitigation measures that were put in place were around the length, frequency and timetabling of sessions for the programme and the availability of session recordings for all, with clear supporting written explanations. The smaller group sessions were timetabled so that all students at least had live access to these sessions. The purpose of the small group sessions was in-part to allow a 'safer' space in which students could ask questions in smaller groups and to a $\mathrm{PhD}$ student, to breakdown potential issues around fear of speaking-up in the larger 
https://doi.org/10.5194/gc-2021-36

Preprint. Discussion started: 8 October 2021

(c) Author(s) 2021. CC BY 4.0 License.

(c) (i)

full-class setting and to more senior staff members. Although, a 'there's no such thing as a silly question' philosophy was imbued such mitigations can be hard to permeate and to be accepted within student cohorts.

\section{Perceptions}

First, we consider the responses to the quantitative statements and then go onto consider the qualitative free text of participants in response to the two questions posed and the open question option.

\subsection{Quantitative Statements}

Numerical responses were collated for each statement and plotted as box-and-whisker diagrams. Responses are collated into the three key themes: learning outcomes, peer-peer and academic support and logistics. The key findings are shown in Figures 2, 3 and 4 respectively, and grouped by statement to enable comparison between student and staff response, and pre- and postcourse differences. Averages in the text are quoted to one decimal place, the low number of staff responses should be taken into consideration in any interpretation. Since the questionnaires were anonymised, changes in individual opinion could not be tracked, but by analysing the average, and interquartile ranges (IQR) of the sets of responses it is possible to interpret the collective perceptions of the two cohorts (students and staff) both pre- and post-course, and therefore track changes in perceptions with time. Differences between student and staff perceptions were observed for certain statements, the key observations are described below. It should be noted that one student responded with the most negative option for all the learning outcome statements; from their response to the open question, it was clear that this student was frustrated at not being able to go in the field, and we interpret their responses as reflecting this frustration. Often this negative response is shown as an outlier (a dot) in the box and whisker plots.

\subsubsection{Learning Outcomes}

210 Key responses to the learning outcomes statements are shown in Figure 2. The statement "students are likely to see rocks in their context in the field" (Figure 2a) was typically met with neutral responses prior to the course, with students and staff both scoring the statement with an average response of 2.7 and having the same IQR of 2-3. Post-course, the IQR increased for both cohorts, 2-4 for students and 1-4 for staff. The average student response increased to 3.2 and remained fairly constant for staff at 2.6. For the statement "students are likely to make detailed observations of rock outcrops and fabrics"

215 (Figure 2b), pre-course the students had an average score of 3.1 whilst staff had an average score response of 2.9. Postcourse the IQR for students narrowed to 2.75-3, whilst the staff IQR increased 2-4. The average responses were again similar 2.7 and 2.9 for students and staff respectively.

There was diverse opinion both pre- and post-course for students and staff with regard to the "ability of students to complete sedimentary logs" (Figure 2c), with the IQR spanning 2-4 in all response sets, but most participants agreed that the 
https://doi.org/10.5194/gc-2021-36

Preprint. Discussion started: 8 October 2021

(c) Author(s) 2021. CC BY 4.0 License.

(c) (i)

"interpretation and analysis of sedimentary logs" would be possible (Figure 2d), with an IQR of 4-5 for both cohorts preand post-course; the collective opinion remaining almost unchanged post-course with the average range across all response sets of 4.3-4.4. Similarly, students and staff were optimistic about the "interpretation of structural data" (Figure 2e) pre- and post-course, the IQR was 4-5 and the average score ranged from 4.1-4.6; similar too were responses to the "interpretation of

field observations to make predictions" (Figure 2f) with an IQR of 4-5. Note that these statements do not refer to the method of data collection, so the responses do not refer to the acquisition of field data, only the use of that data.

Students and staff predicted that they would be able to "build and maintain a field notebook" (Figure 2g), IQR 4-5 (students) and 3-4.25 (staff) in the pre-course questionnaire, broadening to an IQR of 3-5 for students and decreasing slightly to an IQR of 3-4 for staff in the post-course questionnaire. Students were unsure about their potential "ability to interpret field observations to build a geological history" (Figure 2h) prior to the course, with responses across a range of 2 to 5 recorded, but with an IQR of 3.25-4.75 and an average of 3.9 (agreement). Post-course, the IQR range narrowed 4-5, and shifted with an average score of 4.5. Post-course staff responses mirrored those of the student cohort with the same IQR range 4-5 and an average score of 4.6. For a similar statement on being able to "synthesise datasets to create maps, cross sections, and interpretations" (Figure 2i) students and staff had a neutral to positive opinion pre-course with IQR ranges of 3-5 and 3-4 respectively. Post-course the IQR was 4-5 for both cohorts and the average score increased to 4.4 and 4.1 for students and staff respectively.

\subsubsection{Peer \& Academic Support}

There was diverse opinion both pre- and post-course on whether peer-to-peer learning and group cohesion would be significantly reduced compared to an actual field trip (Figure 3a and b). Average scores for "peer-to-peer learning for staff and students" both pre- and post-course indicated that this aspect was thought likely to be impacted, with IQRs across a range of 2.75-5; average scores did fall for students from 4.2 to 3.9, pre- to post-course, and for staff 3.7 pre-course to 3.6 postcourse. Prior to the course, students were unsure as to the "level of academic support that they would receive as individuals" (Figure 3c), with an average value of 2.6, an IQR 1.25-3 and a full response range of 1-5. The range of opinions on completion

245 of the course the range was still 1-5, but the IQR had shifted to 2.75-5 and the average score to 3.5. Pre-course, staff were also unsure, with an average score of 3, and an IQR of 2-4. Post-course, staff opinions were similar to the pre-course, with the same IQR and an average of 3.1. A similar positive shift is seen in terms of "academic staff support for the group as a whole" (Figure 3d). 
https://doi.org/10.5194/gc-2021-36

Preprint. Discussion started: 8 October 2021

(c) Author(s) 2021. CC BY 4.0 License.

\subsubsection{Logistics}

Regarding the length of the course, students and staff responded to two statements comparing a five-week period of distributed learning, with a 10-day intensive course, one question focusing on the benefit to them as individuals and the other on the benefit to the group. There was a broad spread in response to both questions (Figure $4 \mathrm{a}$ and b). But both cohorts, students and staff, felt that the extended five-week time period was "beneficial to individual students", with pre-course average scores of 3.5 (students) and 3.0 (staff) and 3.4 (students) and 3.7 (staff) post-course. For the "benefit of the group as a whole", there was a similar trend with average scores pre-course of 3.9 (students) and 3.1 (staff) to 3.7 (students) and 3.3 (staff) post-course.

Students predicted a range of outcomes regarding "internet issues affecting progress" (Figure 4c). The full range of responses, $1-5$, were submitted by students' pre-course, but the average value shifted towards little impact, from values of 2.7 and 3.4 precourse for students and staff respectively to 2.4 and 2.7 post-course. Opinion on the value of a printed workbook was generally positive (Figure 4d-f). Students were unsure as to the usefulness of a workbook in terms of "finding a quiet space to work" in advance of the course (Figure 4d) (IQR 2.25-4), whereas staff believed it would be useful (IQR 4-5). Post-course the response was neutral from students, with an average score of 3.1, but with an IQR spanning 1-5. In terms of a workbook allowing "students to reflect on their work away from a screen" (Figure 4e), both students and staff agreed that this was true with positively skewed and narrow IQR ranges across pre- and post-course questionnaires, and a range in average scores of 4.1-4.4. Students believed that the workbook would "provide a resource for future reference" (Figure 4f) (average scores of 4.3 and 4.4 pre- and post-course); staff scored this statement with an average score of 3.7 pre- and post-course, still positive, but not as positive as the student cohort.

\subsection{Qualitative Statements}

The questionnaire asked for long text answers to two questions, one on the positive aspects of a virtual field course the second on negative aspects. At the end of each of the questionnaires there was also free text space for respondents to add anything additional that they felt had not been covered in the preceding statements. Seven staff members involved in the course design and delivery provided free text comments before and after the field trip, along with 20 of the participating students, in advance of the field trip, and 14 afterwards. They highlighted issues ranging from technical aspects of virtual environments and field trips through to learning outcomes and experiences. Many provided context and reasoning for their scoring responses to the preceding questions, with free text responses clearly being led, to some extent, by the preceding quantitative questions. Ten codes were created after analysis of the free text (see 3.2 Questionnaire Analysis) and classified as positive and negative (Table 1), in which the full set of coded data is summarised. Figure 5 shows radar plots of the same data to visually represent the preand post-course perceptions of students and staff respectively (Figure $5 \mathrm{a}$ and b), and comparison of staff and student perceptions pre course (Figure 5c) and post-course (Figure 5d). The radar plots are 'split' vertically with positive aspects on the right-side and negative aspects on the left-side. We describe the results of each radar plot in turn. 
https://doi.org/10.5194/gc-2021-36

Preprint. Discussion started: 8 October 2021

(c) Author(s) 2021. CC BY 4.0 License.

(c) (i)

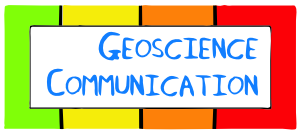

Discussions

\subsubsection{Pre- and post-course student perceptions}

The radar plot of pre- and post-course student perceptions (Figure 5a) shows little change in student perceptions on the aspects that they raised over the course. The majority of change lies within the positive half of the plot, notably around positive aspects of online teaching and learning with $71 \%$ of respondents mentioning this after the course in comparison to $19 \%$ pre-course.

285 Negative aspect of online teaching and learning complement this with a decrease from $63 \%$ pre-course to $50 \%$ post-course mentions. Time management also shows a positive shift post-course from $25 \%$ pre-course to $36 \%$ post-course, but this is balanced by negative mentions which increase from $19 \%$ pre-course to $36 \%$ post-course. Mentions of negative issues related to software/hardware and Wi-Fi problems also increase from $25 \%$ pre-course to $36 \%$ post-course.

\subsubsection{Pre- and post-course staff perceptions}

290 Figure $5 \mathrm{~b}$ illustrates the changes in staff perceptions pre-and post-course. Staff perceptions show some changes pre- and postcourse. Comments on the negative aspects of the virtual field trip are dominant and increase slightly over the course from $71 \%$ to $86 \%$. Concerns around inequality, inaccessibility and exclusion decrease from a pre-course percentage of $14 \%$ to zero postcourse, this is mirrored by a similar decrease in positive comments around accessibility, equality and inclusion $57 \%$ to $29 \%$ suggesting a neutral stance. Mentions of positive perceptions on the breadth in learning outcomes and experience decrease 295 slightly during the course from $57 \%$ to $43 \%$, while comments on the benefits of virtual field trips remain constant. Concerns of staff regarding time management appeared during the course rising from no negative comments' pre-course to $43 \%$ postcourse. This is supported by a decrease in positive comments on time management from the pre-course analysis of $43 \%$ to $29 \%$ post-course.

\subsubsection{Pre-course perceptions of students and staff}

300 Figure 5c, enables comparison of student and staff perceptions pre-course. The shape of the radar plots for the two cohorts show a similarity in pre-course perceptions between staff and students with negative aspects of the virtual field trip featuring most strongly for both cohorts $88 \%$ and $71 \%$ respectively. Students and staff appeared to have similar, but relatively low, levels of concern regarding inequality, inaccessibility and exclusion $19 \%$ students and $14 \%$ staff. Students were more concerned (63\%) than staff $(29 \%)$ about the negative aspects of online teaching and learning. Staff felt that there would be 305 positive implications for accessibility, equality and inclusion (57\%) whereas students barely mentioned this (13\%). Positive aspects regarding breadth in learning outcomes and experiences (50\% students, $57 \%$ staff) and benefits of virtual field trips ( $56 \%$ students, $43 \%$ staff) were similar. Concerns regarding time management were zero for staff and $19 \%$ for students. 
https://doi.org/10.5194/gc-2021-36

Preprint. Discussion started: 8 October 2021

(c) Author(s) 2021. CC BY 4.0 License.

\subsubsection{Post-course perceptions of students and staff}

310 Figure 5d, enables comparison of student and staff perceptions post-course. The shape of the radar plots show both similarity and divergence. Negative aspects of the virtual field trip feature strongly for both cohorts $88 \%$ students and $86 \%$ staff. Students' mention inequality, inaccessibility and exclusion (21\%) whereas staff do not. Students (50\%) and staff (57\%) have post-course concerns around negative aspects of online teaching and learning. Perhaps surprisingly students commented on the positive aspects of the online teaching and learning environment more (71\%) and were divergent from staff (14\%). Staff were more positive (29\%) regarding accessibility, equality and inclusion than the students (14\%). Breadth in learning outcomes and experience were mentioned by $50 \%$ of students and by $43 \%$ of staff respondents. Students $(57 \%)$ and staff $(43 \%)$ both recognized benefits of the virtual field trip.

\section{Discussion}

The exercise of running the virtual field trip and eliciting perceptions, provided an opportunity to really consider the impact of online course design and delivery choices on student learning and experience. The aim was simply to use the opportunity to reflect on online and virtual field teaching environments and practices to inform future teaching strategies and pedagogy. We discuss the findings of our research through a series of questions.

\subsection{Were learning outcomes met?}

Before the course staff held several sessions to discuss how best to design and deliver the virtual field trip, these included both consideration of learning outcomes and identification of areas or elements of online learning and virtual field trips that might raise concerns in terms of delivery and learning. Despite not being in the field staff felt in advance of the virtual field trip that all the main learning outcomes could be met, apart from physically observing rocks in the field. On reflection the evidence in terms of the main learning outcomes was that the breadth of learning outcomes was met or exceeded. There was a recognition that the types of skills and learning outcomes were different and broader in scope than those that might have been learnt on an actual field trip. This is reflected by positive perceptions around the breadth of learning outcomes and experience, a fall in the perception of negative perceptions of online teaching and learning by both staff and students, and high scoring of statemnets by students and staff on abilities in interpretation and data synthesis. So, although skills such as physically taking strike and dip measurements in the field had not been met, manipulating such measurements in on online stereonet packages and analysing larger datasets were, for example, much expanded in comparison to an actual field trip. Students also recognised that they had more time to work on data, analysing and synthesising it to expand their understanding and learning, such as thinking about and creating cross-sections that worked with their maps to visualise a fully 3D subsurface space. Although, not analysed here the students performed well in the module assessment and in post-course reflections staff felt that the students learning outcomes had exceeded those from an actual field trip. So, although specific techniques such as field measurements had not been taught the students ability to manipulate and analyse data had exceeded expectations. These types of skills in 
https://doi.org/10.5194/gc-2021-36

Preprint. Discussion started: 8 October 2021

(c) Author(s) 2021. CC BY 4.0 License.

(c) (i)

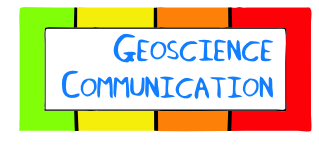

Discussions

critical thinking and analysis are developed through time and are transferable across disciplines and hence in many ways are more desirable than a specific ability to undertake a technique or measurement which can be learnt at any stage.

\subsection{Were pre-identified concerns lived out, and were mitigations measures effective?}

Staff identified concerns they had about students' ability to participate fully in the online field trip in advance of the course. These included internet connectivity, time and space to learn, as well as issues with engagement and cohort cohesion. The

results from online internet tests that the students undertook in advance of the course indicated that student internet speeds were poor relative to data for the whole of the UK and globally at the time of the course. The mitigations put in place included recording all sessions and providing a printed workbook for students to refer to alongside online course material. The exercises were designed so they could be completed without the need to access 3D virtual outcrop models, with these elements adding value rather than being critical. The pre-course and post-course perceptions of students and staff indicate that these mitigation measures were at least partially successful, although rendering of large 3D virtual outcrop models caused a problem for some. The workbook compensated, at least to some extent, in terms of exercise completion; although we recognize for student perceptions of inclusion this mitigating strategy could have negative implications.

\subsubsection{Length of Virtual Field Trip}

Students recognized the benefits to themselves personally, as well as for the group of running the course over a five-week time period. The length of time was difficult for some as they were concerned with changes to rules and regulations with regard to dynamic COVID-19 restrictions, evolving work commitments, and the ability to travel to see relatives amongst other things. We believe that this mainly reflects the uncertainty of the period rather than anything specifically with the delivery. Time management was perhaps the most significant issue that resulted from delivery over a five-week period. For students effectively in lockdown at home there was a tendency to spend a considerable amount of time, beyond that advised on the tasks and exercises. Students felt in some instances that staff had underestimated the amount of time to undertake some of the exercises. These negative aspects of time management, alongside the positive aspects of being in control of when they chose to learn are clearly reflected in the questionnaire and statement responses. We believe that the time committed by students, beyond that expected, resulted in a greater breadth and depth of learning. The extended length of time for delivery also allowed techniques and concepts to embed and skills to develop, particularly critical analysis and synthesis. This work ethic was

365 reflected by high module grades. But raises conflicting concerns around time management, mental fatigue and student welfare when home working, especially in a lockdown scenario in which the world is all work with little opportunity for 'play'.

\subsubsection{Recorded sessions}

Evidence from the online learning environment and verbal feedback from students indicated that they did go back and watch recorded sessions, including Q\&A sessions as well as the formal introductions to the different exercises, in their own time to 
https://doi.org/10.5194/gc-2021-36

Preprint. Discussion started: 8 October 2021

(c) Author(s) 2021. CC BY 4.0 License.

(c) (i)

go over material (repeating content) as well as to access elements that they had missed either through clashes with other commitments or due to internet issues. These positive aspects of the online virtual field trip and learning environment were reflected in answers to the questions and the free text.

\subsubsection{Internet connectivity and hardware}

The students' internet connectivity was generally able to cope with the demands of the virtual field trip, although some students did have difficulties rendering some of the larger 3D virtual outcrop models. Some students, and staff, also suffered with maintaining connection to live sessions, and did not use video. But connection data suggest the impact was minimal and that these occurrences did not have an impact on students' performance and progression with the course, with all the students completing the virtual field trip. The average course mark was also high. It is thought that the hardcopy workbook helped to mitigate both hardware and internet connectivity issues.

\subsubsection{Hardcopy workbook}

The workbook was identified by the students as a helpful reference for future learning, although staff perceptions of this were more spread. The workbook was effective for students in terms of allowing them to read and reflect off-screen during the course mitigating internet connectivity issues, as well as ability to manipulate models etc., whilst reading instructions. This was particularly important for students who were often working on relatively small laptop screens.

\subsection{Did the virtual field trip develop student cohesion and peer-peer learning?}

Elements of student cohesion and teamwork that result from an actual field trip, alongside peer-peer learning are often considered one of the benefits of the in-field experience. Staff were concerned that these elements would not be replicated in a virtual field trip. To mitigate, or indeed to try and best replicate these elements students were divided into small groups of five with a PhD student mentor and had drop-in sessions each week to discuss their work and exercises. This helped break down barriers between staff and students and encouraged students to share their work with their peers to discuss issues. Some of these groups worked very well, others were less effective. One group was amalgamated into the other groups part way through the virtual field trip to increase effectiveness this dynamic ability to adapt based on student feedback worked well.

Delivery of the virtual field trip benefitted from a relatively small student cohort that had already worked together in the field and had spent 2.5 years at university ahead of the COVID-19 restrictions. This meant that they were already effectively working

395 well as a cohesive team in advance of the field trip, with their own networks and social media groups which helped with peer support. Students were encouraged to use the chat function in the online learning environment within their small groups and with the whole cohort. However, use of the chat function in the virtual learning environment was limited outside of timetabled 
https://doi.org/10.5194/gc-2021-36

Preprint. Discussion started: 8 October 2021

(c) Author(s) 2021. CC BY 4.0 License.

(c) (i)

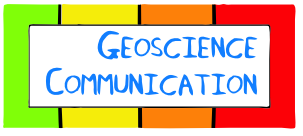

Discussions

live Q\&A sessions; although these live sessions were run frequently (minimum daily) throughout the virtual field trip, so extra questions may not have been required.

\subsection{Was academic-student support effective?}

There was some concern around how effective student support from staff would be in the online environment. Students were positive in terms of many of the aspects of the online teaching and learning environment, the free text responses indicate that students appreciated the large number of staff and student sessions and the ratio of staff: students. For example, actual field trips for a student cohort of 22 may have 2 teaching staff and 1 or $2 \mathrm{PhD}$ student demonstrators whereas there were 3-4 lecturers available at any one time and $5 \mathrm{PhD}$ student demonstrators for the virtual field trip. It was felt by both staff and students that the increased contact time was beneficial to help identify and work through areas of misunderstanding. There was also more opportunity for students who maybe would not normally engage to ask questions of staff and $\mathrm{PhD}$ students.

\section{Conclusions and Recommendations}

Overall, the virtual field trip could be described as highly successful, if student marks were used as the main indicator of

410 success. Here we have considered broader elements including learning outcomes, peer and academic support and student cohesion. Reflecting on the running of a virtual field trip from student and staff perceptions to inform future online learning, particularly virtual field trips. We recommend consideration of the following elements in virtual field trip delivery:

Hardcopy Workbook - the use of a hardcopy workbook delivered to students allowed them to have a tangible overview of the field trip in advance, it provided an easy-to-use set of reference material, enabled students to work off-screen and to evaluate 415 multiple sources of material: online and hardcopy during a single exercise. It also allowed those with internet connectivity or hardware issues to participate in the virtual field trip and complete exercises solely on paper, although no students were in this position.

Session Recording - we recorded all formal sessions, as well as informal Q\&As. The students used these to refresh material as well as to catch-up on missed sessions. The only sessions not consistently recorded were small student group sessions with $\mathrm{PhD}$ students, as our aim was to make these as informal, relaxed and open as possible. Students were positive about the opportunities' available through the recording of online teaching to catch-up on and revise material in their own time. 
https://doi.org/10.5194/gc-2021-36

Preprint. Discussion started: 8 October 2021

(c) Author(s) 2021. CC BY 4.0 License.

(c) (i)

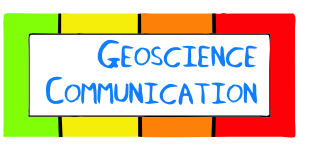

Discussions

Recognition of Challenges - although we did not use the data on internet connectivity beyond identifying students who might have issues. We believe it was reassuring for students to know that we had considered possible barriers to participation in terms of internet connectivity, space to work effectively, other commitments etc. This helped to build trust and a shared understanding, so that when issues did arise students' felt more able to raise them.

Multiple Interaction Opportunities - providing multiple interaction opportunities with both academic staff and PhD students throughout the field trip was important. It is also important to recognize that students will likely also have their own social networks and to build on these.

430 Breadth of Learning Outcomes - our main conclusion is that virtual field trips offer an additional method of training and in many ways compliment actual field trips. They can provide opportunities for greater and different interactions with staff that are not possible when those same staff are also dealing with the logistics of an actual field trip. They provide opportunities for greater synthesis of data and development of critical analytical skills over multiple geological field areas that is hard to replicate on an actual field trip.

435 The radar plots reflect the nuances of positive and negative aspects of virtual field trips. We note that both pre- and post-course, for students and staff, that negative aspects of the virtual field trip dominate comments. But that these are countered by positive comments on aspects of virtual field trips and online teaching and learning and perhaps most notably the breadth in learning outcomes and experience. We can learn from this drawing-on the findings to inform future design and delivery of virtual field trips in a blended-learning environment to expand and develop their positive aspects.

\section{Author Contributions}

CEB lead the virtual field trip, conceived the research, led on staff discussions around learning outcomes, barriers and mitigation measures, deigned and deployed the questionnaires, designed the initial data analysis protocols and completed an initial data analysis, lead on writing the manuscript. JHP acted as $\mathrm{PhD}$ student demonstrator on the virtual field trip and input into initial discussions on course design and delivery, coding discussions of the qualitative text, redrafted all figures for final publication, collected the data for Figure 1 and commented on the final text draft. LK acted as PhD student demonstrator on the virtual field trip and input into initial discussions on course design and delivery, analyzed and created initial box and whisker plots for the quantitative data and inputted into coding discussions of the qualitative text, co-authored the initial draft text for qualitative statement analysis. SRL was a student on the virtual field trip, they input into data compilation, coding of the text-response statements, co-authored the initial draft text for qualitative statement analysis. MZS and TKG were students on the virtual field trip they conducted the initial coding of the qualitative text and input, and drafted some of the methods text, 
https://doi.org/10.5194/gc-2021-36

Preprint. Discussion started: 8 October 2021

(c) Author(s) 2021. CC BY 4.0 License.

(c) (i)

and constructed initial radar plots. MB was a student on the virtual field trip they input into initial discussion and helped with qualitative statement coding.

\section{Acknowledgements}

We acknowledge the input of all students and staff that took part in the virtual field trip and contributed to the research by completing the surveys. Virtual field trip academic staff were Clare Bond, Rob Butler, Malcolm Hole, Colin North, Adrian Hartley, and Ian Alsop who were involved in discussions on learning outcomes course design and delivery modes. The nonauthor PhD student demonstrators were Tom Theurer, Bartosz Kurjanski and Sophie Berhendsen who provided feedback on small group sessions.

\section{References}

460 Abduvakhidov, A.M., Mannapova, E.T. and Akhmetshin, E.M.: Digital Development of Education and Universities: Global Challenges of the Digital Economy, International Journal of Instruction, 14.1, 743-760. 2021.

Arthurs, L.A.: Bringing the Field to Students during COVID-19 and Beyond, GSA Today, 31, 28-29, https://doi.org/10.1130/GSATG478GW.1, 2021.

Bond, C.E. and Cawood, A.J.: A role for virtual outcrop models in blended learning-improved 3D thinking and positive 465 perceptions of learning. Geoscience Communication, 4, 2, 233-244, https://doi.org/10.5194/gc-4-233-2021, 2021.

Bos, D., Miller, S. and Bull, E.: Using virtual reality (VR) for teaching and learning in geography: fieldwork, analytical skills, and employability, Journal of Geography in Higher Education, 1-10, https://doi.org/10.1080/03098265.2021.1901867, 2021. Boyle, A., Maguire, S., Martin, A., Milsom, C., Nash, R., Rawlinson, S., Turner, A., Wurthmann, S. and Conchie, S.: Fieldwork is good: The student perception and the affective domain, Journal of Geography in Higher Education, 31, 2, 299-317, https://doi.org/10.1080/03098260601063628, 2007.

Buckley, S.J., Enge, H.D., Carlsson, C. and Howell, J.A.:Terrestrial laser scanning for use in virtual outcrop geology, The Photogrammetric Record, 25, 131, 225-239, https://doi.org/10.1111/j.1477-9730.2010.00585.x, 2010.

Buckley S.J., Howell J.A., Naumann N., Lewis C., Chmielewska M, Ringdal K., Vanbiervliet J., Tong B, Mulelid-Tynes O. S., Foster D., Maxwell G., Pugsley J.H.: V3Geo: a cloud-based repository for virtual 3D models in geoscience, Geoscience 475 Communication, this volume, in review.

Çaliskan, O.: Virtual field trips in education of earth and environmental sciences, Procedia-Social and Behavioral Sciences, 15, 3239-3243, https://doi.org/10.1016/j.sbspro.2011.04.278, 2011.

Casini, G., Hunt, D.W., Monsen, E. and Bounaim, A.: Fracture characterization and modeling from virtual outcrops, AAPG Bulletin, 100, 1, 41-61, https://doi.org/10.1306/09141514228, 2016. 
https://doi.org/10.5194/gc-2021-36

Preprint. Discussion started: 8 October 2021

(c) Author(s) 2021. CC BY 4.0 License.

(c) (i)

480 Christie, H., Tett, L., Cree, V.E., Hounsell, J. and McCune, V.: A real rollercoaster of confidence and emotions: Learning to be a university student, Studies in higher education, 33, 5, 567-581, https://doi.org/10.1080/03075070802373040, 2008.

Cleveland-Innes, M. and Campbell, P.: Emotional presence, learning, and the online learning environment. The International Review of Research in Open and Distributed Learning, 13, 4, 269-292, https://doi.org/10.19173/irrodl.v13i4.1234, 2012.

Devkota, K.R.: Inequalities reinforced through online and distance education in the age of COVID-19: The case of higher education in Nepal, International Review of Education, 67, 145-165, https://doi.org/10.1007/s11159-021-09886-x, 2021.

Hess, G.F.: Heads and hearts: The teaching and learning environment in law school, J. Legal Educ., 52, 75, 2002.

Hurst, S.D.: Use of "virtual" field trips in teaching introductory geology, Computers \& Geosciences, 24, 7, 653-658, https://doi.org/10.1016/S0098-3004(98)00043-0, 1998.

Iacobucci, G.: Covid-19: UK lockdown is "crucial" to saving lives, say doctors and scientists, BMJ, 368, 490 https://doi.org/10.1136/bmj.m1204, 2020.

Laksana, D.N.L.: Implementation of online learning in the pandemic covid-19: Student perception in areas with minimum internet access, Journal of Education Technology, 4, 4, 502-509, http://dx.doi.org/10.23887/jet.v4i4.29314, 2021.

Martínez-Graña, A.M., Goy, J.L. and Cimarra, C.A.: A virtual tour of geological heritage: Valourising geodiversity using Google Earth and QR code, Computers \& Geosciences, 61, 83-93, https://doi.org/10.1016/j.cageo.2013.07.020, 2013.

495 Mead, C., Buxner, S., Bruce, G., Taylor, W., Semken, S. and Anbar, A.D.: Immersive, interactive virtual field trips promote science learning, Journal of Geoscience Education, 67, 2, 131-142, https://doi.org/10.1080/10899995.2019.1565285, 2019.

Ochieng, V.O. and Gyasi, R.M.: Open educational resources and social justice: Potentials and implications for research productivity in higher educational institutions, E-Learning and Digital Media, 18, 2, 105-124, https://doi.org/10.1177/2042753021989467, 2021.

500 Pasquaré Mariotto, F. and Bonali, F.L.: Virtual geosites as innovative tools for geoheritage popularization: A case study from Eastern Iceland. Geosciences, 11, 4, 149, https://doi.org/10.3390/geosciences11040149, 2021.

Pearson W., Reddy V.: Social Justice and Education in the Twenty-First Century. In: Pearson Jr. W., Reddy V. (eds) Social Justice and Education in the 21st Century. Diversity and Inclusion Research. Springer, Cham. https://doi.org/10.1007/978-3030-65417-7_1, 2021.

505 Pringle, J.K., Westerman, R. and Gardiner, A.R.: Virtual geological outcrops-fieldwork and analysis made less exhaustive?, Geology Today, 20, 2, 64-69, https://doi.org/10.1111/j.1365-2451.2004.00450.x, 2004.

Rotzien, J.R., Sincavage, R., Pellowski, C., Gavillot, Y., Filkorn, H., Cooper, S., Shannon, J., Yildiz, U., Sawyer, F. and Uzunlar, N.: Field-Based Geoscience Education during the COVID-19 Pandemic: Planning, Execution, Outcomes, and Forecasts, GSA Today, 31, 4-10, https://doi.org/10.1130/GSATG483A.1, 2021.

510 Sanders, C.K. and Scanlon, E.: The digital divide is a human rights issue: Advancing social inclusion through social work advocacy, Journal of Human Rights and Social Work, 6, 130-143, https://doi.org/10.1007/s41134-020-00147-9, 2021. 
https://doi.org/10.5194/gc-2021-36

Preprint. Discussion started: 8 October 2021

(c) Author(s) 2021. CC BY 4.0 License.

(c) (i)

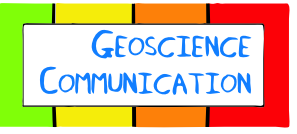

Discussions

Stokes, A. and Boyle, A.P.: The undergraduate geoscience fieldwork experience: Influencing factors and implications for learning. In: Whitmeyer, S. J., Mogk, D.W., Pyle, E.J. (eds) Field geology education: Historical perspectives and modern approaches, GSA, 461, 291. 2009.

Tibaldi, A., Bonali, F.L., Vitello, F., Delage, E., Nomikou, P., Antoniou, V., Becciani, U., de Vries, B.V.W., Krokos, M. and Whitworth, M.: Real world-based immersive Virtual Reality for research, teaching and communication in volcanology, Bulletin of Volcanology, 82, 38, https://doi.org/10.1007/s00445-020-01376-6, 2020.

Tinto, V.: Learning better together: The impact of learning communities on the persistence of low-income students,

Opportunity Matters, 5-21, 2008.

Trinks, I., Clegg, P., McCaffrey, K., Jones, R., Hobbs, R., Holdsworth, B., Holliman, N., Imber, J., Waggott, S. and Wilson, R.: Mapping and analysing virtual outcrops, Visual Geosciences, 10, 13-19, https://doi.org/10.1007/s10069-005-0026-9, 2005. Tuthill, G. and Klemm, E.B.: Virtual field trips: Alternatives to actual field trips, International Journal of Instructional Media, 29, 453-468, 2002.

Whitmeyer, S.J. and Dordevic, M.: Creating virtual geologic mapping exercises in a changing world. Geosphere, 17, 226-243, https://doi.org/10.1130/GES02308.1, 2021.

Xia, J.: Analysis of impact of culture shock on individual psychology. International Journal of Psychological Studies, 1, 2, 97101, 2009.
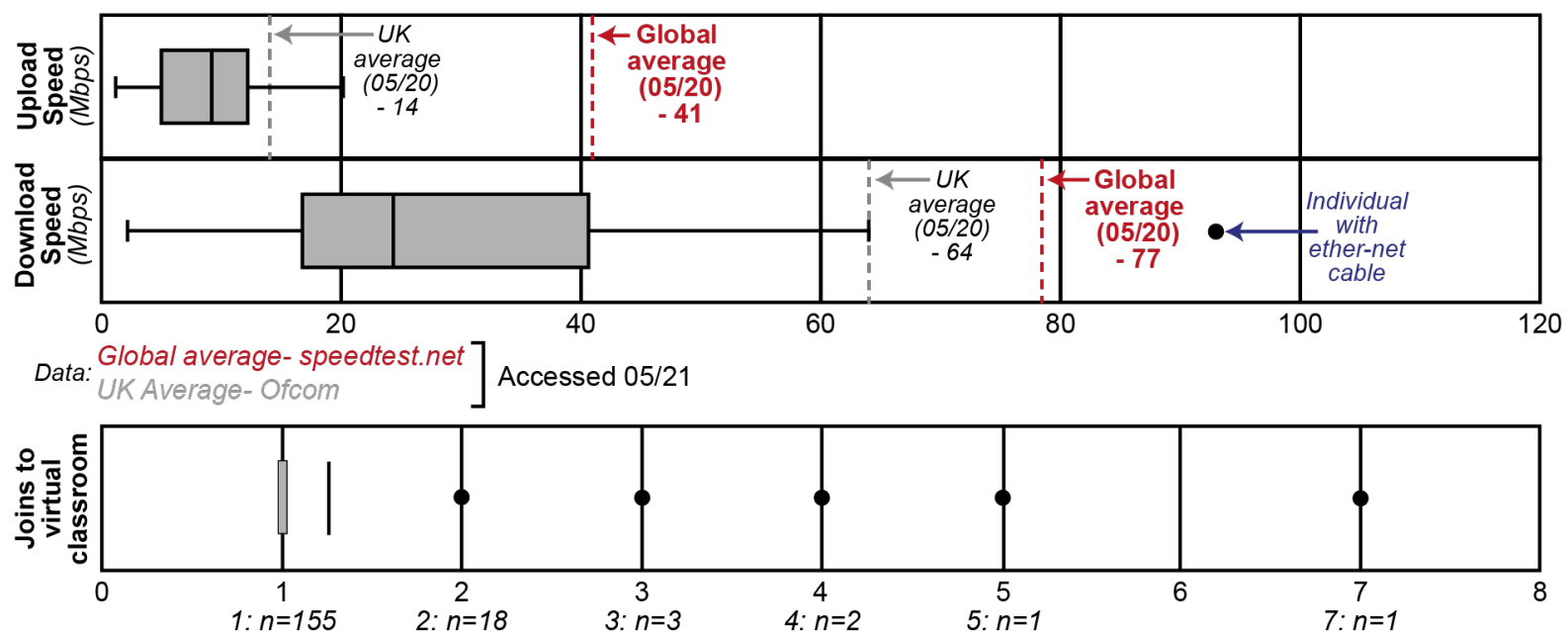

Figure 1: Internet speed and connectivity data. a) Student internet upload and download speeds presented in Mbps, and plotted as full and interquartile ranges, with averages marked. The student cohort data are compared to UK and global averages for the same time period as the virtual field trip (May 2020). Note that the one student with an ether-net cable plots as an outlier for download speeds. b) Data from the online student classroom that summaries the number of joins per session to the virtual classroom to 22 live online sessions over the five-week virtual field trip. 


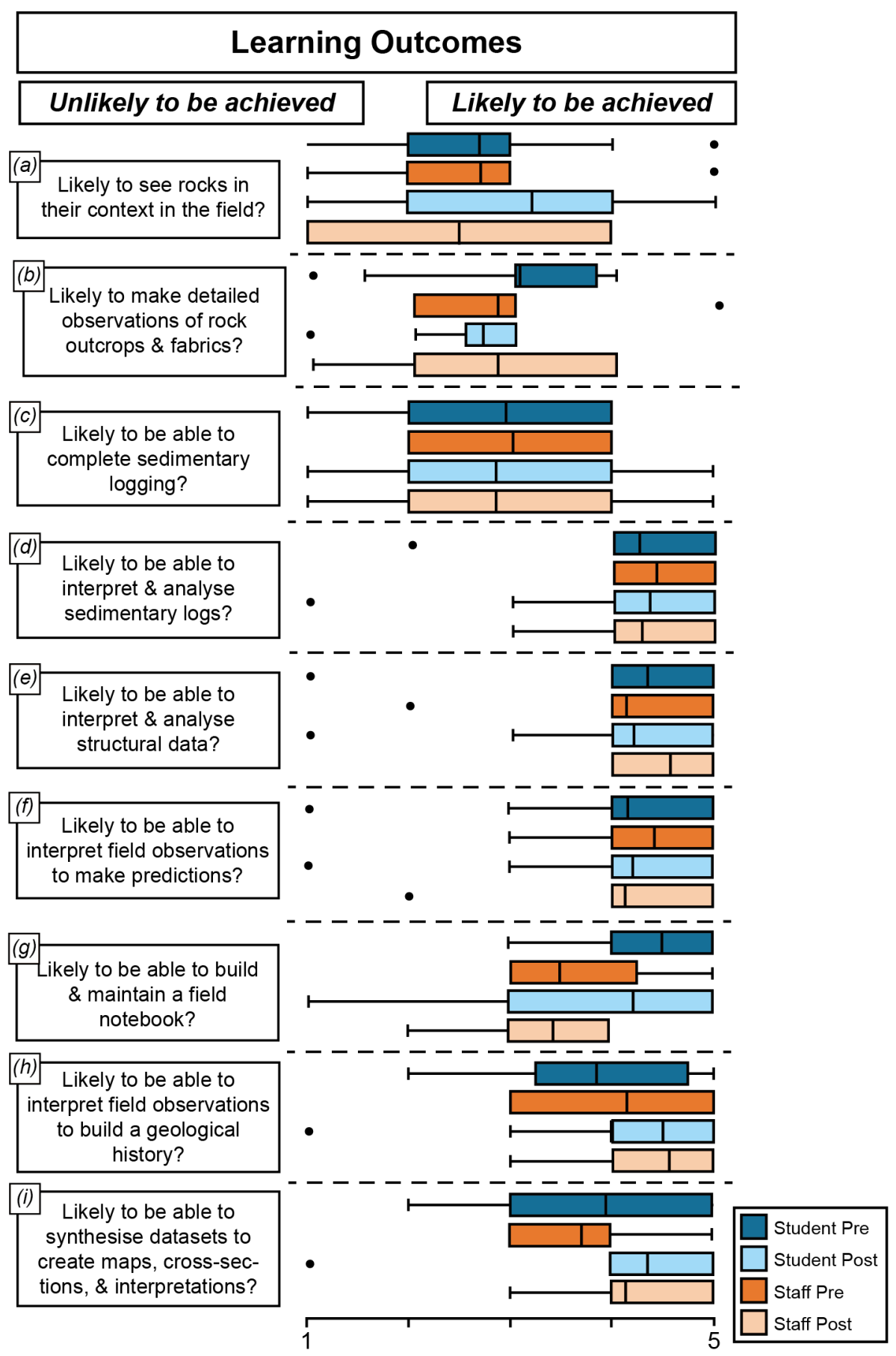

Figure 2. Quantitative responses to learning outcome statements. a)-i) Summarise staff and student responses on a scale of 1-5, where 1 is unlikely to be achieved and 5 is likely to achieved for a series of statements on learning outcomes. Responses are grouped by statement and presented as pre-course and post-course for the student and staff cohorts. 


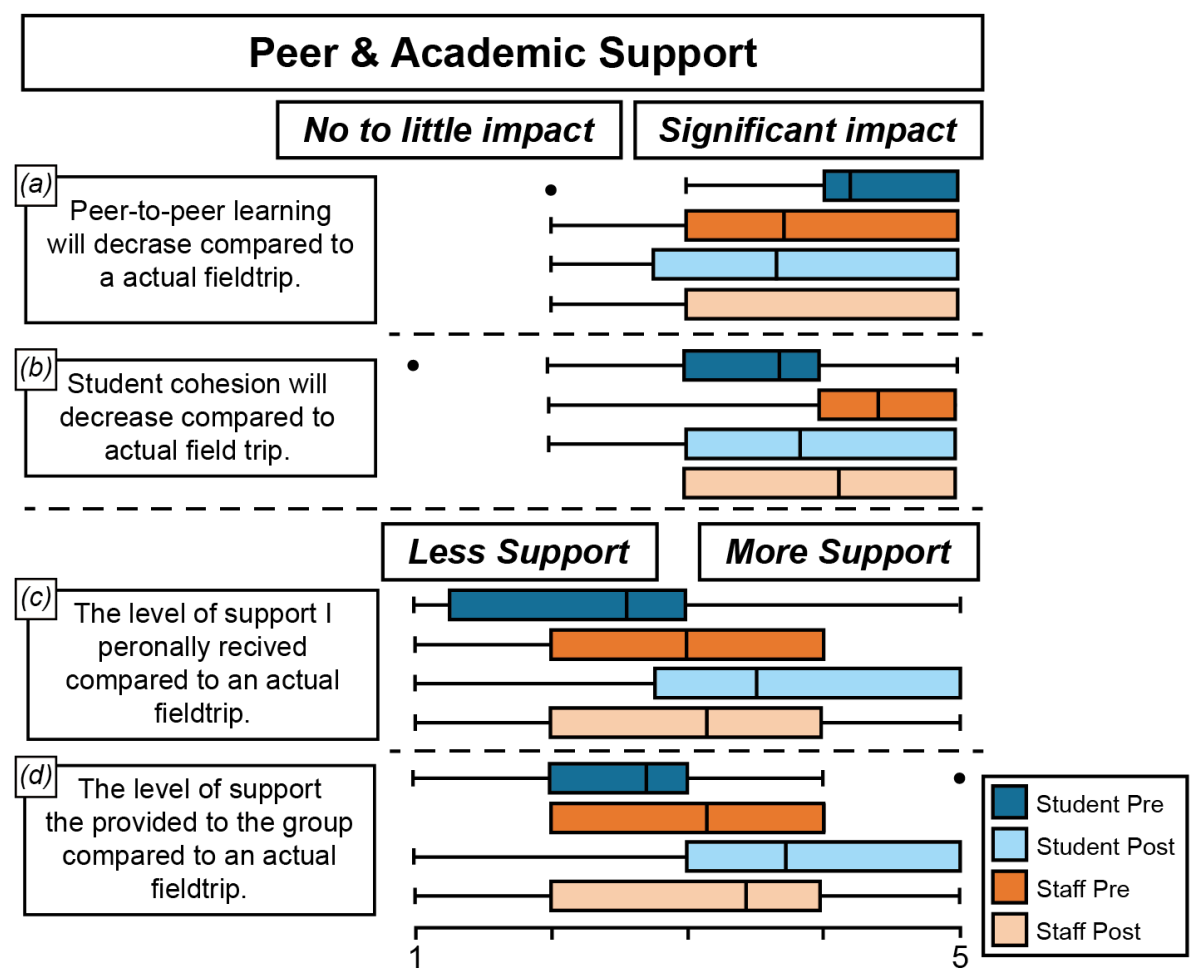

Figure 3. Quantitative responses to peer and academic support statements. a) \& b) Summarise staff and student responses on a scale of 1-5, where 1 is no to little impact and 5 is significant impact on statements related to peer-peer learning and student cohesion. c) \& d) Staff and Student responses to statements on support level where 1 in less support and 5 is more support. Responses are grouped by statement and presented as pre-course and post-course for the student and staff cohorts. 


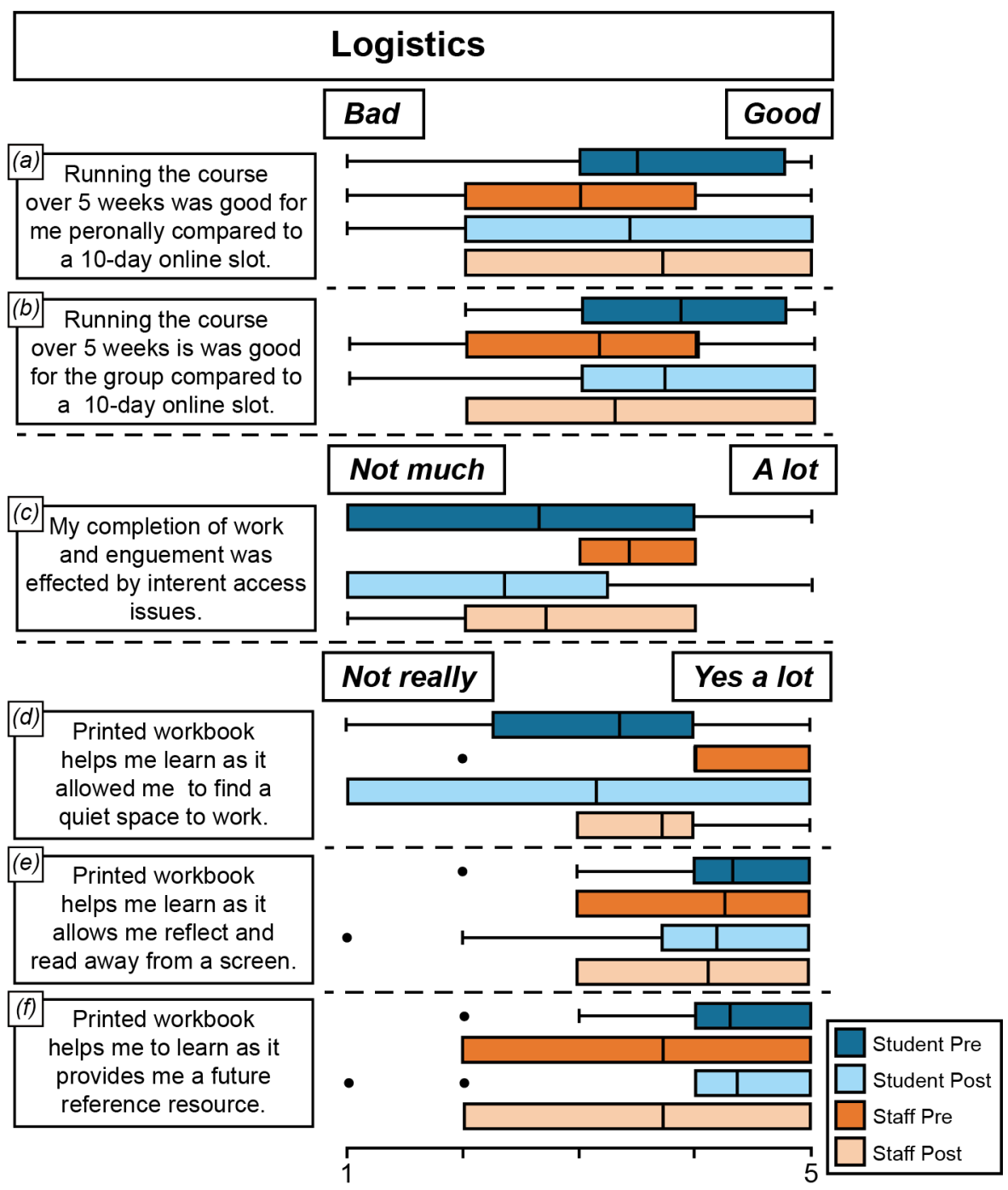

Figure 4. Quantitative responses to logistics statements. a) \& b) Summarise staff and student responses on a scale of 1-5, where 1 is bad and 5 is good for statements related to the length of the virtual field trip. c) Staff and student responses to statements on the impact of internet access issues on completion of the course, where 1 is not much and 5 is a lot. d)-f) Staff and student responses regarding the usefulness of printed workbooks, where 1 is not really and 5 yes a lot. Responses are grouped by statement and presented as pre-course and post-course for the student and staff cohorts. 
https://doi.org/10.5194/gc-2021-36

Preprint. Discussion started: 8 October 2021

(c) Author(s) 2021. CC BY 4.0 License.
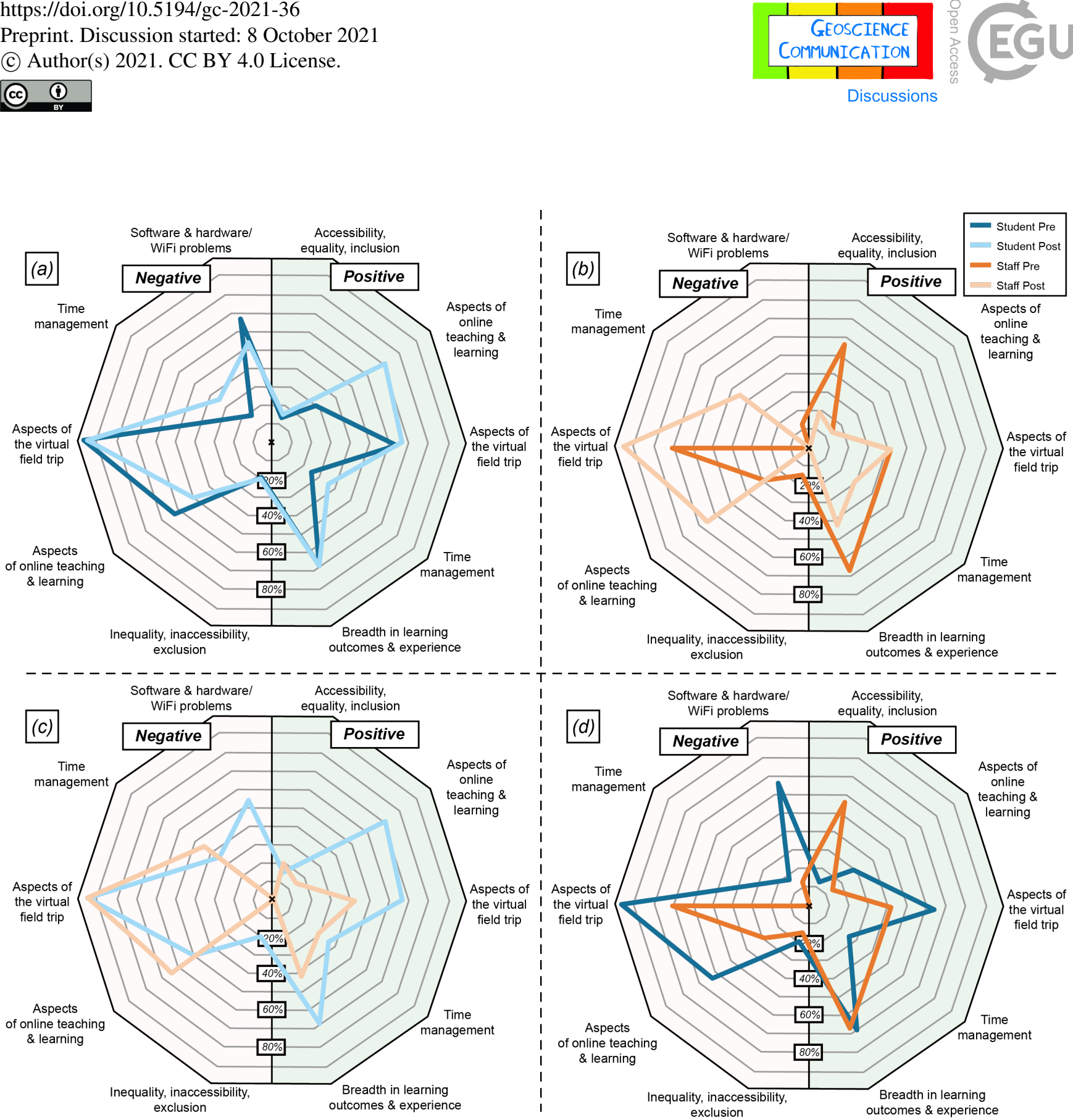

Figure 5. Radar plots of student and staff perceptions derived from free text responses to questions. a) Student perceptions pre- and post-course, b) Staff perceptions pre- and post-course, c) Comparison of student and staff perceptions pre-course, d) Comparison of student and staff perceptions post-course. The plots are split vertically with negative elements on the left and positive on the right, positive and negative equivalents are plotted opposite each other, except for two independent codes. 
https://doi.org/10.5194/gc-2021-36

Preprint. Discussion started: 8 October 2021

(c) Author(s) 2021. CC BY 4.0 License.

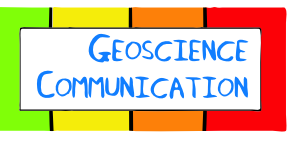

Discussions

\begin{tabular}{|c|c|c|c|c|c|c|c|c|c|}
\hline & & \multicolumn{4}{|c|}{ Students } & \multicolumn{4}{|c|}{ Staff } \\
\hline & & \multicolumn{2}{|c|}{ Pre } & \multicolumn{2}{|c|}{ Post } & \multicolumn{2}{|c|}{ Pre } & \multicolumn{2}{|c|}{ Post } \\
\hline \multicolumn{2}{|l|}{ Code Title } & $(\%)$ & Frequency & (\%) & Frequency & (\%) & Frequency & $(\%)$ & Frequency \\
\hline Accessibility, equality, inclusion & $+\mathrm{ve}$ & 13 & 2 & 14 & 2 & 57 & 4 & 29 & 2 \\
\hline Inequality, inaccessibility, exclusion & -ve & 19 & 3 & 21 & 3 & 14 & 1 & 0 & 0 \\
\hline \multirow{2}{*}{ Aspects of the online teaching \& learning } & $+\mathrm{ve}$ & 19 & 3 & 71 & 10 & 14 & 1 & 14 & 1 \\
\hline & -ve & 63 & 10 & 50 & 7 & 29 & 2 & 57 & 4 \\
\hline \multirow{2}{*}{ Aspects of the virtual fieldtrip } & $+\mathrm{ve}$ & 56 & 9 & 57 & 8 & 43 & 3 & 43 & 3 \\
\hline & -ve & 88 & 14 & 86 & 12 & 71 & 5 & 86 & 6 \\
\hline \multirow{2}{*}{ Time Management Positive } & $+\mathrm{ve}$ & 25 & 4 & 36 & 5 & 43 & 3 & 29 & 2 \\
\hline & -ve & 19 & 3 & 36 & 5 & 0 & 0 & 43 & 3 \\
\hline Breadth in learning outcomes \& experience & $+\mathrm{ve}$ & 50 & 8 & 50 & 7 & 57 & 4 & 43 & 3 \\
\hline \multirow[t]{2}{*}{ Software \& hardware/WiFi problems } & -ve & 25 & 4 & 36 & 5 & 14 & 1 & 0 & 0 \\
\hline & & & $n=16$ & & $n=14$ & & $n=7$ & & $n=7$ \\
\hline
\end{tabular}

Table 1. Summary of qualitative text coding. The table shows the ten codes and frequency and percentage of coded occurrences, this data is plotted in figure 5 . 